\title{
Numerical Investigation of Nanofluid Forced Convection in Channels with Discrete Heat Sources
}

\author{
Payam Rahim Mashaei, Seyed Mostafa Hosseinalipour, \\ and Mehdi Bahiraei
}

CAE Lab \& CFD Center, Mechanical Engineering Department, Faculty of Engineering, Iran University of Science \& Technology (IUST), Tehran, Iran

Correspondence should be addressed to Mehdi Bahiraei, bahira@iust.ac.ir

Received 6 January 2012; Revised 21 January 2012; Accepted 22 January 2012

Academic Editor: M. F. El-Amin

Copyright (C) 2012 Payam Rahim Mashaei et al. This is an open access article distributed under the Creative Commons Attribution License, which permits unrestricted use, distribution, and reproduction in any medium, provided the original work is properly cited.

Numerical simulation is performed to investigate the laminar force convection of $\mathrm{Al}_{2} \mathrm{O}_{3} /$ water nanofluid in a flow channel with discrete heat sources. The heat sources are placed on the bottom wall of channel which produce much thermal energy that must be evacuated from the system. The remaining surfaces of channel are kept adiabatic to exchange energy between nanofluid and heat sources. In the present study the effects of Reynolds number ( $\operatorname{Re}=50,100,200,400$, and $1000)$, particle volume fraction $(\phi=0$ (distilled water), 1 and $4 \%$ ) on the average heat transfer coefficient $(h)$, pressure drop $(\Delta P)$, and wall temperature $\left(T_{w}\right)$ are evaluated. The use of nanofluid can produce an asymmetric velocity along the height of the channel. The results show a maximum value $38 \%$ increase in average heat transfer coefficient and $68 \%$ increase in pressure drop for all the considered cases when compared to basefluid (i.e., water). It is also observed that the wall temperature decreases remarkably as Re and $\phi$ increase. Finally, thermal-hydraulic performance $(\eta)$ is evaluated and it is seen that best performance can be obtained for $\operatorname{Re}=1000$ and $\phi=4 \%$.

\section{Introduction}

Localized areas of high temperature on microprocessors and various electronic components produce hot spots that have an unfavorable effect on their performance and operating conditions. With increasing of power density of these electronic components, good attempts have been carried out to enhance the heat exchanger rate of them by active as well as passive methods. While the former usually offers higher augmentation, it requires additional external forces that can increase the capital and operating cost of the system. In contrast, passive heat transfer enhancement can be obtained by changing the geometry or modifying thermal properties of working fluid [1]. In recent years, the advances in manufacturing technology 
have caused the production of nanoparticles and created a special class of fluids, called "nanofluids". The term "nanofluid" refers to a two-phase mixture where the continuous phase is usually a liquid and the dispersed phase is created of extremely fine metallic particles of size about $50 \mathrm{~nm}$, called "nanoparticles" [2].

Many researchers experimentally showed nanofluids have higher thermal conductivity than those of the base fluids and a lot of correlations were reported. For example Lee et al. [3] evaluated $\mathrm{Al}_{2} \mathrm{O}_{3}$-water/ethylene glycol with particle diameters 24.4 and $38.4 \mathrm{~nm}$ as well as $\mathrm{CuO}$-water/ethylene glycol with particle diameters 18.6 and $23.6 \mathrm{~nm}$ and showed that thermal conductivity increases to $20 \%$ as particle volume fraction increases from 0 to $4 \%$. Chopkar el al. [4] measured thermal conductivity of $\mathrm{Ag}_{2} \mathrm{Al}$-water nanofluids and $\mathrm{Al}_{2} \mathrm{Cu}$ water nanofluids and found that it increases about $130 \%$ with a volume fraction less than $1 \%$. Some researchers [5-7] investigated the thermal conductivity of nanofluids as a function of volume fraction and temperature. They showed that the thermal conductivity of nanofluids remarkably increases as temperature rises. Wang and Mujumdar [8] listed a large number of correlations, which are available in the literatures, for thermal conductivity of nanofluids.

Santra et al. [11] numerically studied the effect of $\mathrm{CuO}$-water nanofluid as a cooling medium to simulate the heat transfer behavior in a two-dimensional (infinite depth) horizontal rectangular duct, where top and bottom walls were two isothermal symmetric heat sources. They considered the fluid Newtonian as well as non-Newtonian for a wide range of Reynolds numbers and solid volume fractions. These authors observed that the heat transfer enhancement is possible using nanofluid in comparison with conventional fluid for the both cases. Maiga et al. [12] numerically investigated the flow and thermal behavior of water- $\mathrm{Al}_{2} \mathrm{O}_{3}$ and Ethylene Glycol- $\mathrm{Al}_{2} \mathrm{O}_{3}$ mixtures for a system of parallel, coaxial, and heated disks. A remarkable augmentation of heat transfer coefficient has been observed with increasing of the volume fraction of nanoparticles for both nanofluids. They have reported that the rate of increase of heat transfer is more for Ethylene Glycol- $\mathrm{Al}_{2} \mathrm{O}_{3}$ nanofluid in comparison with the water- $\mathrm{Al}_{2} \mathrm{O}_{3}$ nanofluid. However, the wall shear stress also increases considerably with increasing of volume fraction of nanoparticles. Feng and Kleinstreuer [13] executed a numerical simulation for alumina-water nanofluid flow with heat transfer between parallel disks. They reported that nanofluid produce smoother flow fields and temperature distributions and heat transfer rate increases with higher volume fraction, smaller nanoparticle diameter, reduced disk spacing, and larger inlet Reynolds number.

With respect the problem under study, that is, heat transfer of discrete heat sources in channel flows, there are numerous works [14-17], both numerical and experimental, which consider such a problem.

Bhowmik et al. [14] performed steady-state experiments to investigate general heat transfer from an in-line four simulated electronic chips in a vertical rectangular channel employing water as the fluid working. They evaluated the effects of heat fluxes, flow rate, and geometrical parameters on heat transfer coefficient and illustrated heat transfer rate strongly depends on flow rate. da Silva et al. [15] employed two different analytical approaches to determine how to arrange discrete heat sources on wall cooled by force convection: (i) large number of small heat sources and (ii) small number of heat sources with finite length, which are mounted on a flat wall. Both analyses proved that heat sources should be placed nonuniformly on the wall. Arquis et al. [16] numerically examined the fluid flow and heat transfer characteristics associated with cooling an in-line array of discrete heated blocks in a channel by using a single laminar slot air jet. They studied the effects of various values such as channel height, slot weight, jet Reynolds number, spacing between blocks, block height, and block thermal conductivities. In general, the heat transfer rate increases with the increase 


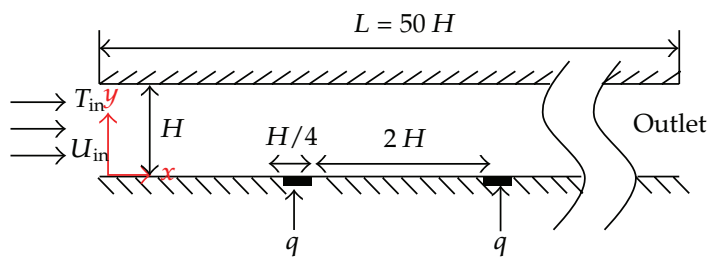

Figure 1: Parallel plates channel with discrete heat sources.

of Reynolds number and the decrease of channel weight. The effective cooling of blocks is observed to increase for shorter and widely spaced heated blocks. Jassim and Muzychka [17] studied the problem how to allocate discrete heat source to the space on a wall of a convergent flow. They showed that the heat sources should be distributed nonuniformly. Furthermore, the optimal spacing between heat sources depends on both Reynolds number and channel shape factor.

In the present paper, the flow and heat transfer characteristics of channel flow with discrete heat sources for base fluid (distilled water) and a nanofluid that is composed of distilled water and $\mathrm{Al}_{2} \mathrm{O}_{3}$ nanoparticles are numerically investigated. The main aim of this study is how the nanofluid affects on the heat transfer rate and pressure drop of flow in a channel with hot spots.

\section{Mathematical Formulation}

\subsection{Geometry Configuration}

In this study the velocity and temperature fields are determined in a parallel plates channel with height $H$ and Length $L$, as shown in Figure 1. The length of duct is 50 times more than height. Nineteen heat sources of $q$ of length $H / 4$ are placed on the bottom wall of the channel. The remaining bottom wall and whole top wall are isolated. The spacing between heat sources is $2 H$.

\subsection{Governing Equations and Boundary Conditions}

Since nanofluids are composed of extremely small particles, it is assumed that the nanoparticles and basefluid are in thermal equilibrium and they flow at same velocity. In the present work, the nanofluid is considered incompressible with temperature-dependent properties. The compression work and viscous dissipation terms were considered negligible in the energy equation. Under such assumptions, the general governing equations written are as the followings.

Conservation of mass:

$$
\nabla\left(\rho_{\mathrm{nf}} V\right)=0
$$

Conservation of momentum:

$$
\nabla \cdot\left(\rho_{\mathrm{nf}} V V\right)=-\nabla P+\mu_{\mathrm{nf}} \nabla^{2} V
$$


Conservation of energy:

$$
\nabla \cdot\left(\rho_{\mathrm{nf}} V\left(C_{p}\right)_{\mathrm{nf}} T\right)=\nabla \cdot\left(k_{\mathrm{nf}} \nabla T\right)
$$

Equations (2.1)-(2.3) must be solve by using appropriate boundary conditions. The flow boundary conditions are a uniform velocity at the channel inlet, equal to $V_{0}$, no-slip at the channel walls and zero relative pressure at channel outlet. The thermal boundary conditions are a uniform temperature at the channel entrance, equal to $T_{0}$ and an adiabatic condition at channel walls, except along the heat sources, in which a uniform heat flux is applied.

\subsection{Nanofluid Thermophysical Properties}

The thermophysical properties of nanofluid are chiefly functions of particle volumetric concentration and temperature. In the absence of experimental data, nanofluid density and specific heat are defined only as a function of volume fraction as follow.

Density:

$$
\rho_{\mathrm{nf}}=(1-\phi) \rho_{\mathrm{bf}}+\phi \rho_{p}
$$

Specific heat:

$$
\left(C_{P}\right)_{\mathrm{nf}}=(1-\phi)\left(C_{P}\right)_{\mathrm{bf}}+\phi\left(C_{p}\right)_{p}
$$

In above equations, subscripts "bf", " $p$ " and "nf" refer to basefluid, nanoparticle and the nanofluid, respectively.

Viscosity:

$$
\begin{array}{ll}
\mu_{\mathrm{nf}}=2.9 \times 10^{-7} T^{2}-2.0 \times 10^{-4} T+0.034 & \text { for } \phi=1 \%, \\
\mu_{\mathrm{nf}}=3.4 \times 10^{-7} T^{2}-2.3 \times 10^{-4} T+0.039 & \text { for } \phi=4 \% .
\end{array}
$$

Thermal conductivity:

$$
\begin{array}{ll}
k_{\mathrm{nf}}=0.003352 \times T-0.3708 & \text { for } \phi=1 \%, \\
k_{\mathrm{nf}}=0.004961 \times T-0.8078 & \text { for } \phi=4 \% .
\end{array}
$$

Equations (2.6) to (2.8) were presented by Roy et al. [18] for water- $\mathrm{Al}_{2} \mathrm{O}_{3}$ nanofluid based on available experimental results published by Putra et al. [19].

\section{Numerical Method}

The governing differential equations are solved using the control volume method. A second order upwind method is used for energy and momentum equations. The SIMPLE procedure 


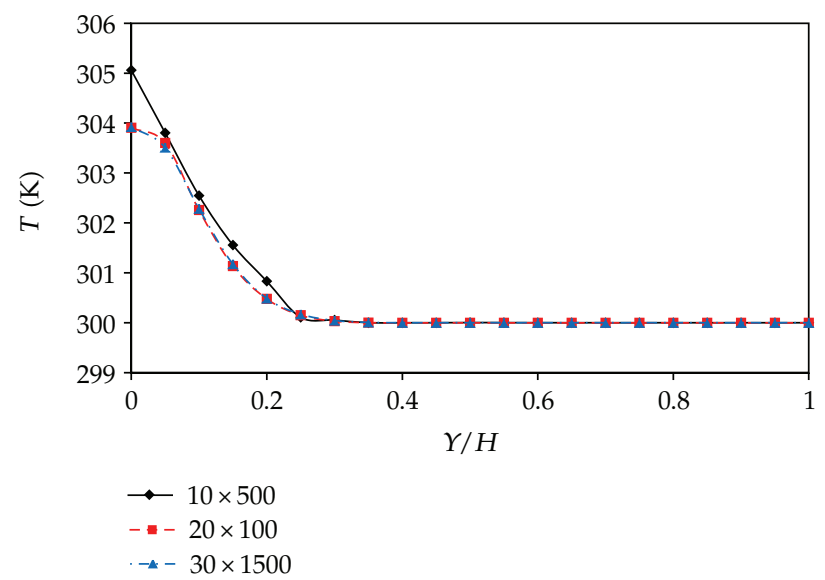

Figure 2: Effect of grid density on the temperature of channel outlet $(\operatorname{Re}=1000, \phi=4 \%, q=6000)$.

is chosen to couple pressure and velocity. The solution converge was met when the normalized residuals for all equations reached to the $10^{-7}$. The algebraic discretized equations throughout the physical domain are solved by means of well-known TDMA techniques.

In order to assess the grid independent of numerical solution, three grid densities are checked. Figure 2 illustrates the effect of grid size on the predicted temperature at outlet channel for $\operatorname{Re}=1000$ and $\phi=4 \%$. As it can be seen a grid density of $20 \times 1000$ provides satisfactory solution for the shown example.

\section{Results and Discussion}

The thermal performance of the channel is characterized in terms of average heat transfer coefficient along the heat sources, $h_{\text {ave, }}$ defined as:

$$
h_{\mathrm{ave}}=\frac{\int h_{s} d s}{19(H / 4)}
$$

where $s$ is the coordinate along the heat sources and $h_{s}$ is given by

$$
h_{s}=\frac{q^{\prime \prime}}{\left(T_{0}-T_{w}\right)},
$$

where $q^{\prime \prime}$ and $T_{w}$ are heat flux of heat sources and wall temperature, respectively.

Thermalhydraulic performance factor is defined as:

$$
\eta=\frac{h_{r}}{(\Delta P)_{r}^{1 / 3}}
$$

where $h_{r}$ and $\Delta P_{r}$ are, respectively, average heat transfer coefficient and pressure drop ratio, referred to values obtained for basefluid. 
The heat transfer performance of cooling channel is discussed in term of the figure of merit, FoM, which is given by [1]

$$
\mathrm{FoM}=\frac{W}{W_{\text {pump }}}
$$

Here $W_{\text {pump }}$ is the pumping power, which is given as:

$$
W_{\text {pump }}=\frac{1}{\eta_{\text {pump }}} \dot{m} \Delta p
$$

where $\eta_{\text {pump }}$ is pump efficiency which assumed to be $70 \%$. The total heat transfer rate is calculated as:

$$
W=\dot{m}\left(C_{p}\right)_{\mathrm{nf}}\left(T_{m, \text { in }}-T_{m, \text { out }}\right)
$$

where, $\dot{m}$ is mass flow rate and $T_{m, \text { in }}$ and $T_{m, \text { out }}$ are mean temperature at inlet and outlet, respectively. Mean temperature is obtained by

$$
T_{m}=\frac{1}{H U_{\text {in }}} \int_{0}^{H} V T d y
$$

\subsection{Code Validation}

In order to show the validity and also accuracy of the model and numerical method, two comparisons with the available data are carried out. The first comparison is related to a parallel plates channel that all its walls are heated with a constant heat flux and the water is used as fluid working. In this case, the Nusselt number is compared which is given by the following definitions:

$$
\mathrm{Nu}=\frac{q H}{k\left(T_{w}-T_{m}\right)}
$$

where $T_{m}$ is bulk temperature of fluid. The comparison is depicted in Figure 3. It is seen that the results of the present study are in good agreement with previous data [9].

The second comparison is concerned with experimental data of nanofluid heat transfer in a circular tube with diameter $(D)$ equal to $4.75 \mathrm{~mm}$ and Length of $1.2 \mathrm{~m}$, given by Anoop et al. [10]. The nanofluid is water- $\mathrm{Al}_{2} \mathrm{O}_{3}$ with $\phi=4 \%$ at a constant Reynolds number 1588 . Figure 4 shows remarkable agreement between the present results on local heat transfer coefficient and those provided by [10]. 


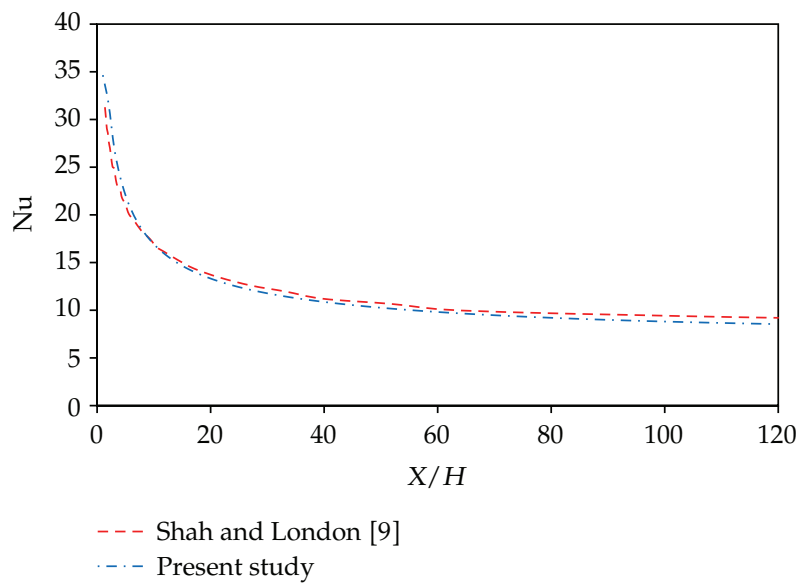

Figure 3: Comparison of present numerical results with those obtained by Shah and London [9].

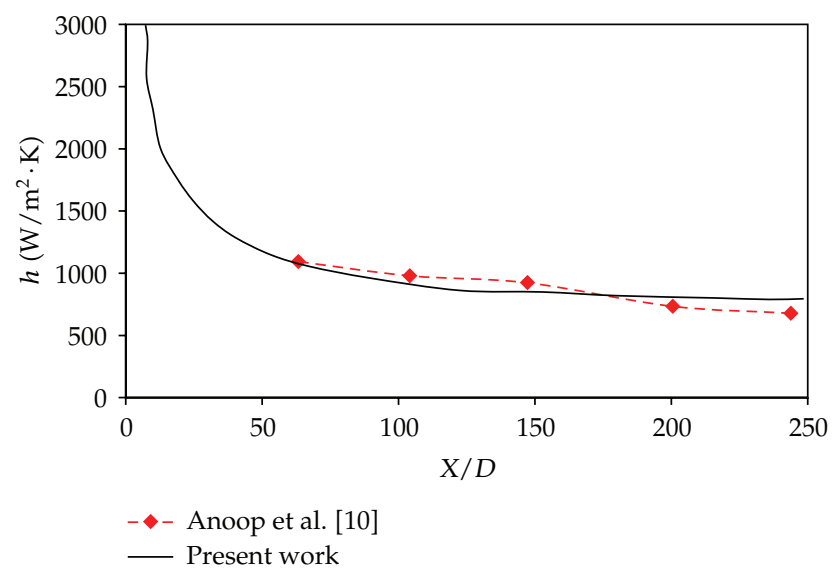

Figure 4: Comparison of heat transfer coefficient between present simulation and experimental data [10] for water- $\mathrm{Al}_{2} \mathrm{O}_{3}$ nanofluid with $\phi=4 \%$ in the circular tube.

\subsection{Velocity Field}

The values of velocity at channel outlet for $\operatorname{Re}=50$ and $\operatorname{Re}=1000$ are depicted in Figures 5(a) and $5(\mathrm{~b})$, respectively, for considered volume fractions. It can be seen that trend of velocity profile is affected by adding the nanoparticle in basefluid for both Reynolds numbers. However, with the increase of nanoparticle loading, as it is expected, the peak of velocity profile will increase. This produces larger velocity gradient near the wall which can lead to increase wall shear stress and pressure drop. Another interesting issue, which one can perceive in Figure 5, is the asymmetric profile for $\phi=1 \%$ and $\phi=4 \%$ because of temperaturedepended viscosity. The magnitude of velocity near the bottom wall is lower due to decreased viscosity. This is because of higher temperature near the bottom wall that decreases the viscosity according to (2.6). The velocity profile is more asymmetric for $\operatorname{Re}=50$ and $\phi=1 \%$. The values of velocity at $Y / H=0.05$ and $Y / H=0.95$ (i.e., near the bottom and top walls) are, respectively, $0.00083 \mathrm{~m} / \mathrm{s}$ and $0.00069 \mathrm{~m} / \mathrm{s}$ for $\operatorname{Re}=1000$ and $\phi=4 \%$ which indicate about 


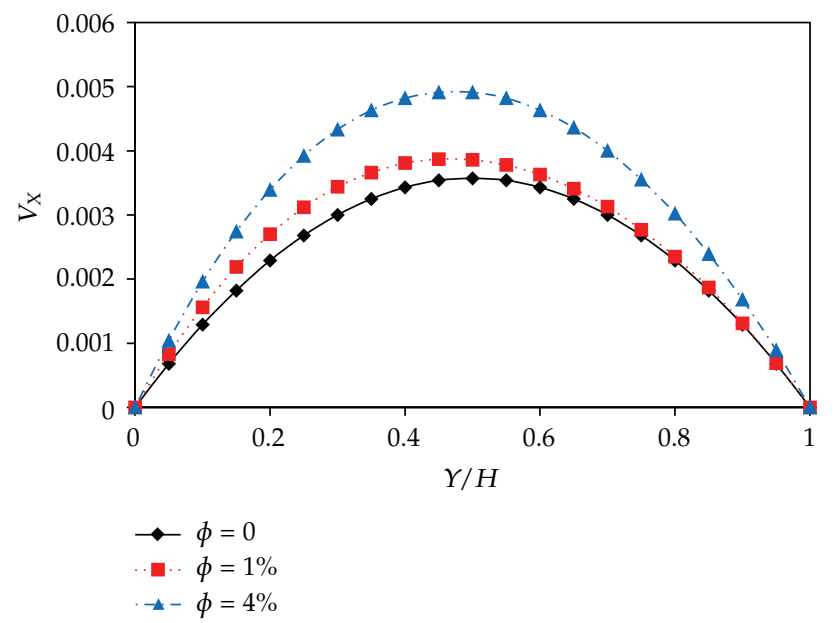

(a)

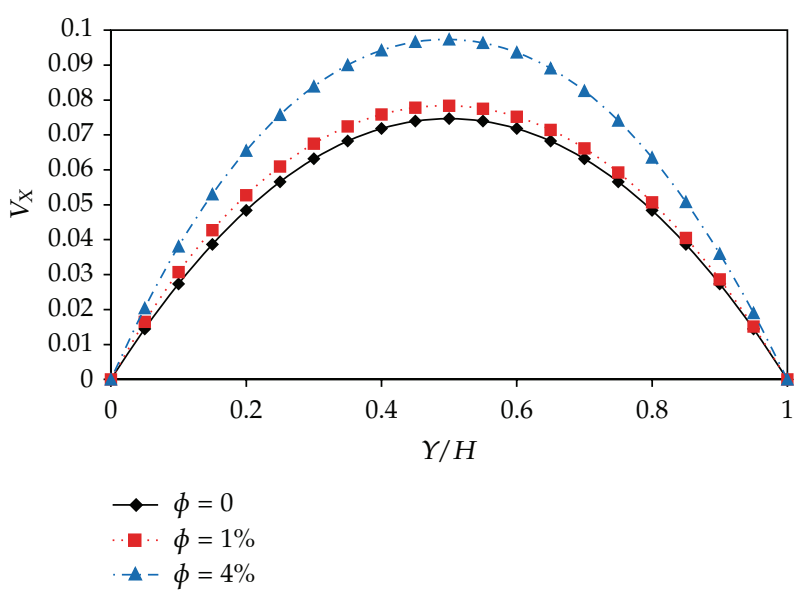

(b)

Figure 5: Effect of particle loading parameter $\phi$ on velocity profile at channel outlet for: (a) $\operatorname{Re}=50,(b)$ $\operatorname{Re}=1000$.

$20 \%$ difference, while this value is equal to 0 (symmetric) and $16 \%$ for $\phi=0$ (distilled water) and $\phi=4 \%$, respectively.

\subsection{Local Nanofluid Properties}

Figures 6(a) and 6(b) show temperature effects on local nanofluid conductivity which is computed inside the numerical model with (2.7) and (2.8). Since the whole top wall is adiabatic and there is no heat transfer, the nanofluid conductivity is only illustrated on bottom wall. One can easily notice that the behavior of nanofluid conductivity is periodic along the channel. This is due the fact that heat sources increase wall temperature and nanofluid conductivity. Furthermore, the remaining bottom wall, which is adiabatic, has lower temperature that leads to lower nanofluid conductivity. With comparison of 


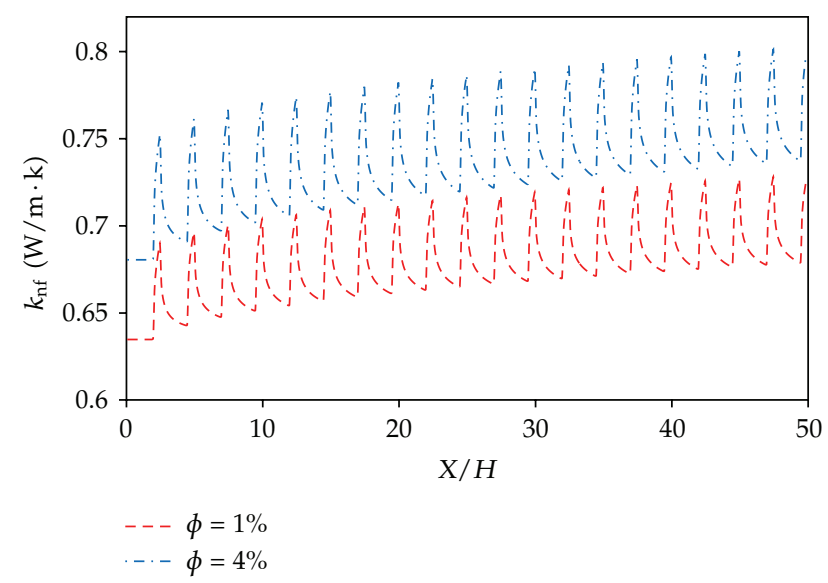

(a)

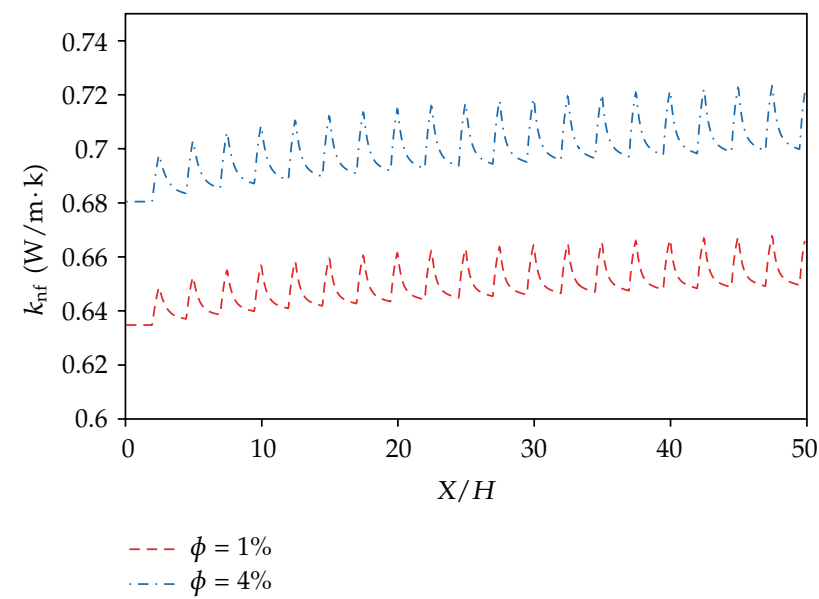

(b)

Figure 6: Effect of particle loading parameter $\phi$ on nanofluid conductivity profile along the channel for: (a) $\operatorname{Re}=50,(b) \operatorname{Re}=1000$.

Figures 6(a) and 6(b), It can be seen that $\operatorname{Re}=50$ presents higher conductivity when compared to $\operatorname{Re}=1000$. The reason is explained as flows. Although the higher Reynolds number increases the heat transfer rate, but, it is not allowed fluid particles to residence for a long time in channel because of its higher mass flow rate. So, for $\operatorname{Re}=50$ the nanofluid temperature rises more in comparison with $\mathrm{Re}=1000$ and presents higher conductivity.

Since the variations of temperature on the top wall is negligible (less than $2 \mathrm{~K}$ ), the local viscosity is illustrated in Figures 7(a) and 7(b) for $\operatorname{Re}=50$ and $\operatorname{Re}=1000$, respectively, only for bottom wall. It can be observed that the local viscosity has a decreasing periodic behavior on bottom wall because of the growing temperature along the channel. As shown in Figure 7, similar to the conductivity profile, the amplitude of variations in a period of local viscosity is higher for $\operatorname{Re}=50$ in comparison with $\mathrm{Re}=1000$. This is due this fact that the lower Reynolds number increases the residence time distribution (RTD) of nanofluid in a period of channel and causes more temperature difference. 


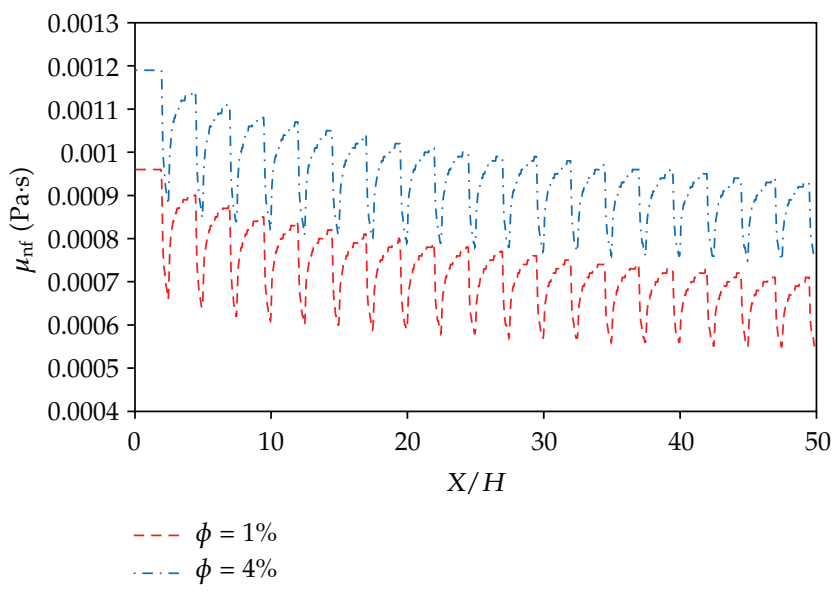

(a)



(b)

Figure 7: Effect of particle loading parameter $\phi$ on nanofluid viscosity along the channel for: (a) $\operatorname{Re}=50$, (b) $\operatorname{Re}=1000$.

\subsection{Effect of Particle Volume Fraction on Heat Transfer and Temperature Field}

Results reveal that the presence of nanoparticles has a remarkable effect on heat transfer enhancement. The average heat transfer coefficient profiles on the heat sources as a function of Reynolds number are depicted in Figure 8(a) for $\phi=0,1$, and 4. In general, the average heat transfer coefficient increases as Reynolds number is increased. It is also observed that as $\phi$ increases $h_{\text {ave }}$ becomes higher for a fixed value of Re. Thus, passing from $\phi=0 \%$ to $\phi=4 \%$, the maximum value of about $2366 \mathrm{~W} / \mathrm{m}^{2} \mathrm{k}$ for $h_{\text {ave }}$ is found at $\operatorname{Re}=1000$ and $\phi=4$.

Figure $8(\mathrm{~b})$ illustrates the average heat transfer coefficient ratio $\left(h_{r}\right)$, referred to the values obtained for basefluid, as a function of Reynolds number for $\phi=0,1$ and $4 \%$. It can be seen that the $h_{r}$ is greater than one for all considered cases and rises slightly as Reynolds number increases from 200 to 1000 for both volume fractions $\phi=1$ and $4 \%$. Furthermore, 




(a)



(b)

Figure 8: Effect of parameters $\phi$ and Re on: (a) average heat transfer coefficient and (b) average heat transfer coefficient ratio.

there is a considerable augmentation for higher volume fraction, in fact the highest value of 1.38 is detected at $\operatorname{Re}=1000$ and $\phi=4 \%$.

As we are also interested to analysis the cooling benefits of nanofluid on bottom wall, Figures 9(a) and 9(b) show the wall temperature for various volume fractions for $\operatorname{Re}=50$ and 1000, respectively. Due to a nonuniform heat flux on bottom wall, an increasing periodic behavior is detected in Figure 9. One can see that the wall temperature is more for Re = 50 in comparison with $\operatorname{Re}=1000$. As mentioned earlier, this is due this fact that the fluid particles spend more time in channel. The peak values of bottom wall temperature are related to the heat sources, while the minimum values belong to adiabatic part of bottom wall. It is also observed that among the considered particle volume fractions, the lowest minimum and maximum values of wall temperature in each period belong to $\phi=4 \%$. It can also be noted the effect of volume fraction on wall cooling becomes more within the farther distance from inlet, that is, greater $\mathrm{X} / \mathrm{H}$. 




(a)

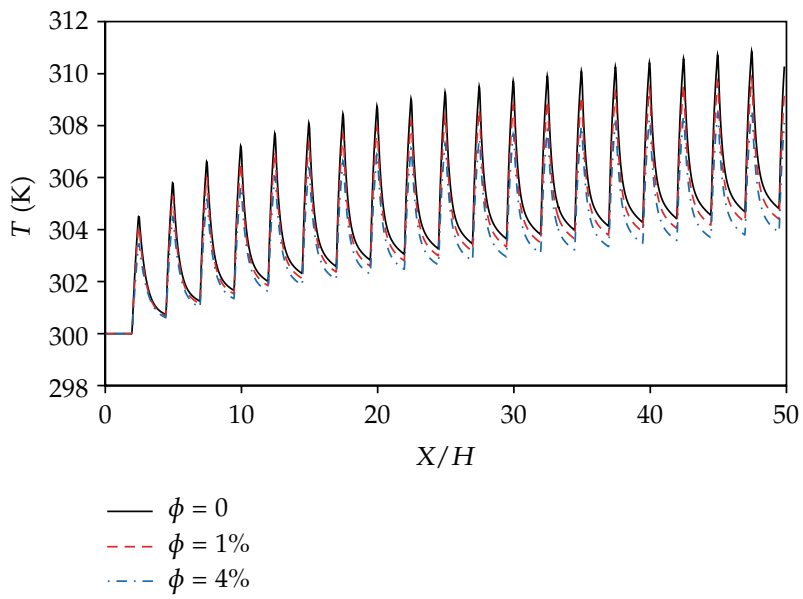

(b)

Figure 9: Effect of particle loading parameter $\phi$ on bottom wall temperature at: (a) $\operatorname{Re}=50$, (b) $\operatorname{Re}=1000$.

The effect of particle volume fraction on temperature along the channel height can be seen on Figures 10(a) and 10(b), depicting the temperature profile at the first of the last heat source for $\operatorname{Re}=50$ and 1000, respectively. It is observed that the values of temperature are higher for $\operatorname{Re}=50$. On the bottom wall, that is, $Y / H=0$, passing from $\operatorname{Re}=50$ to $\operatorname{Re}=1000$ the temperature gradient increases which presents a better heat transfer enhancement. By comparison of Figures 10(a) and 10(b), it is noted that the effect of the use of nanofluid on the temperature along the height of channel is greater for lower Reynolds.

\subsection{Effect of Particle Volume Fraction on Pressure Drop}

It will be predictable that the use of nanoparticles in basefluid can have an adverse influence on pressure drop because of increased viscosity. The pressure drop profiles as a function of 


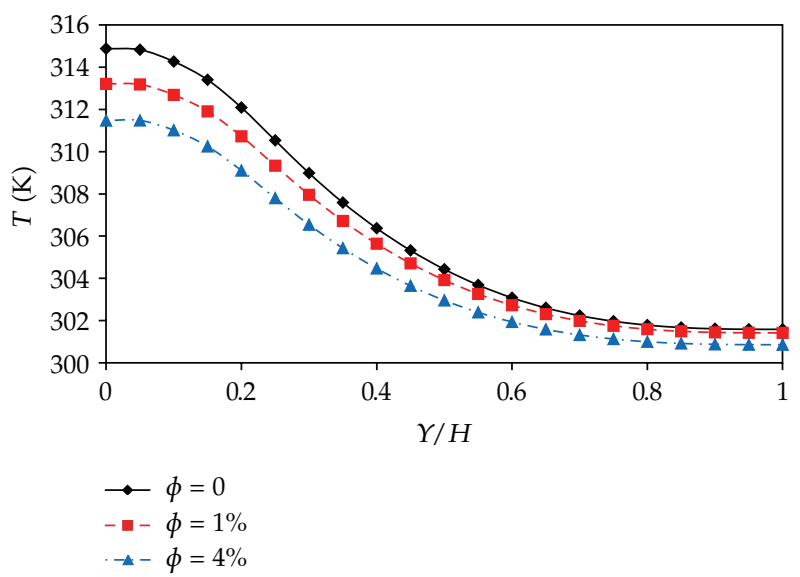

(a)

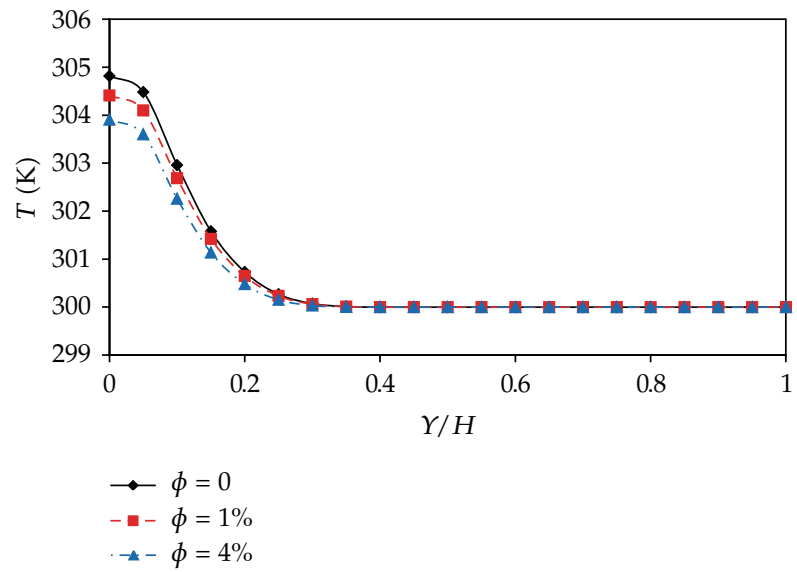

(b)

Figure 10: Effect of volume fraction $\phi$ on temperature profile along channel height at the first of last heat source for: (a) $\operatorname{Re}=50$, (b) $\operatorname{Re}=1000$.

Reynolds number are depicted in Figure 11(a) for $\phi=0,1$, and $4 \%$. As it can be noted, the pressure drop increases as Reynolds number and particle volume fraction increase and the highest value is found at $\operatorname{Re}=1000$ and $\phi=4 \%$. By comparison $\phi=0$, and $\phi=1 \%$, it is observed that the difference between the values of pressure drop is less at lower Reynolds number, while it will be more considerable at higher Reynolds number. This can be explained by the temperature-dependent viscosity of nanofluid.

The pressure drop ratio $\left(\Delta P_{r}\right)$, referred to the base fluid is described in Figure 11(b). It is observed that the $\Delta P_{r}$ is greater than one for all considered cases, similar to $h_{r}$, and rises slightly as Reynolds number increases from 200 to 1000 for both volume fractions $\phi=1$ and $4 \%$. In fact the highest value of pressure drop ratio is equal to 1.68 that is dedicated at $\operatorname{Re}=1000$ and $\phi=4 \%$. 


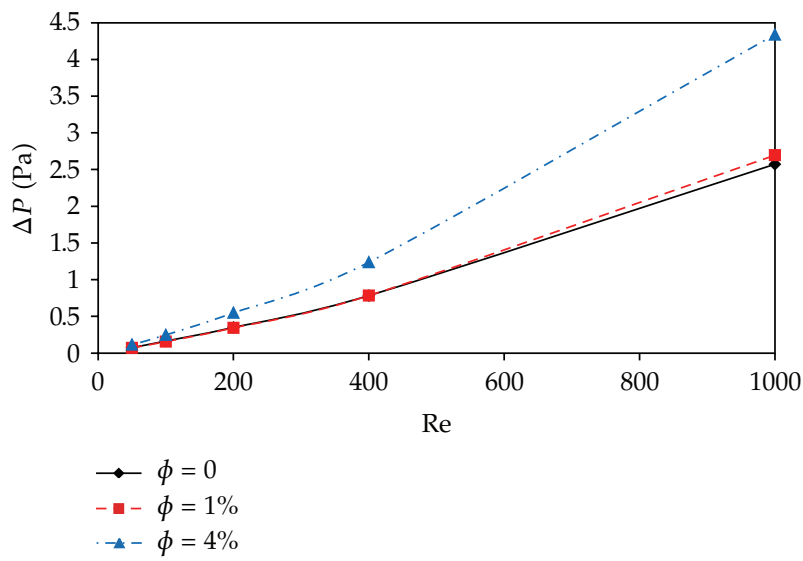

(a)

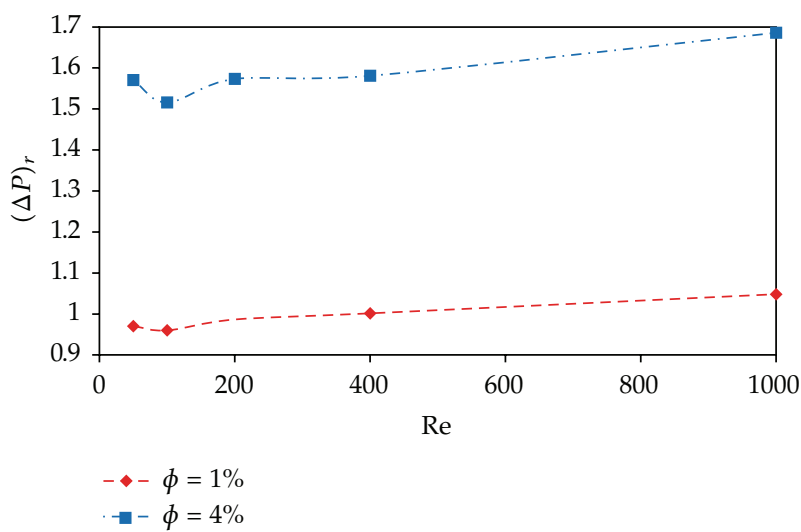

(b)

Figure 11: Effect of parameters $\phi$ and Re on: (a) pressure drop and (b) pressure drop ratio.

\subsection{Effect of Heat Flux of Heat Sources on Heat Transfer and Pressure Drop}

Since we use temperature-dependent properties, it is interesting to determine the effect of heat sources heat flux $(q)$ on heat transfer coefficient and pressure drop. The effects of $(q)$ on the average heat transfer and pressure drop can be seen in Figures 12(a) and 12(b), depicting, respectively, the heat transfer coefficient and pressure drop for $\phi=1$ and $4 \%$. It can easily be seen in Figure 12(a) that the average heat transfer coefficient increases as $(q)$ is increased because of increased nanofluid conductivity. On the other hand, as shown in Figure 12(b), the pressure drop decreases as $(q)$ increases because of decreased nanofluid viscosity. Thus, the augmentation of $(q)$ has a good effect on thermal-hydraulic performance of channel.

\subsection{Thermal Hydraulic and Overall Heat Transfer Performance}

As discussed in previous sections, the use of nanofluids increases the heat transfer rate as well as pressure drop. In order to investigate the order of magnitude of augmentation of heat transfer and pressure drop for various Reynolds number and volume fraction, the thermal 




(a)

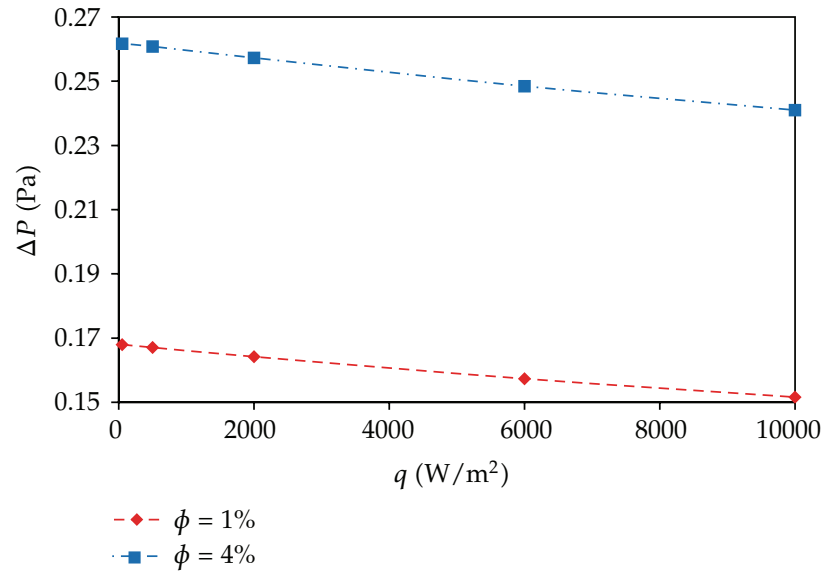

(b)

Figure 12: Effect of parameters $\phi$ and $q$ on (a) averaged heat transfer coefficient and (b) pressure drop. $(\operatorname{Re}=100)$.

hydraulic performance factor as a function of Reynolds number is depicted in Figure 13 for $\phi=1$ and $4 \%$.

It is observed that the thermal hydraulic performance has different behaviors for $\phi=1$ and $4 \%$. For $\phi=1$, thermal hydraulic performance decreases as Reynolds number increases from 50 to 200 and after it, the profile will be unchangeable. For $\phi=4 \%$, thermal hydraulic performance decreases as Reynolds number increases from 50 to 200, similar to $\phi=1 \%$, but there is a remarkable augmentation as Reynolds number increases from 200 to 1000 and the best performance of 1.16 is found at $\operatorname{Re}=1000$ and $\phi=4 \%$.

In order to have a comparison between ratio of output (heat transfer rate) to the input (pumping power), the overal heat transfer performance of channel in term of figure of merit (FoM) as a function of Reynolds number is illustrated in Figure 14 for $\phi=1$ and $4 \%$. It can be seen that FoM decreases as volume fraction increases. This is due this fact that specific heat decreases as volume fraction increases. Furthermore, the increase of volume fraction leads to increased inlet velocity, which decreases residence time distribution of nanofluid. 


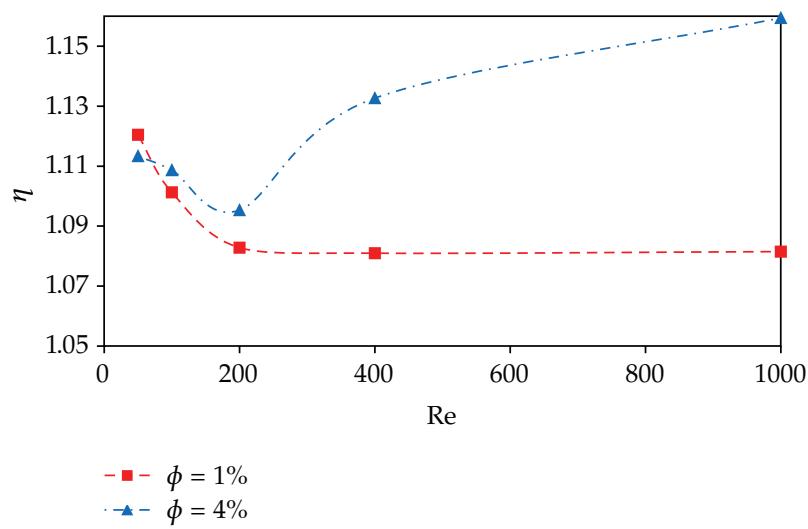

Figure 13: Effect of parameters $\phi$ and $\operatorname{Re}$ on $\eta$.

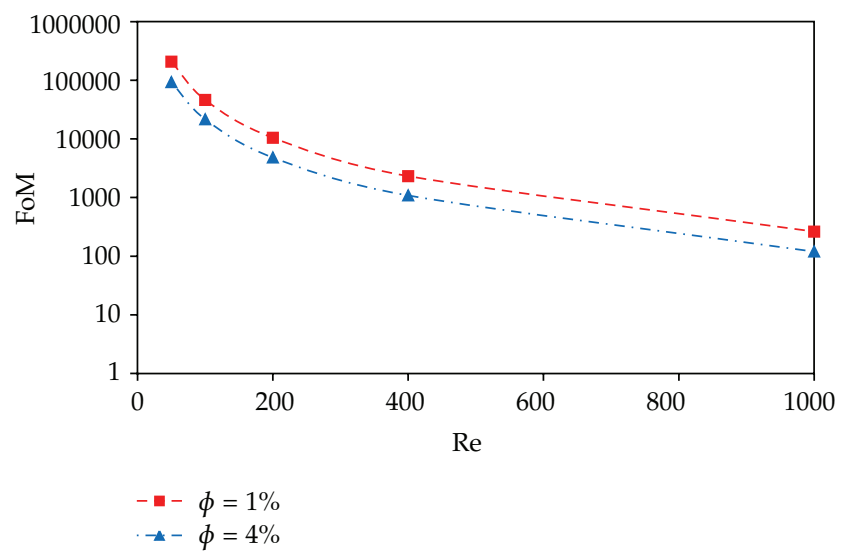

Figure 14: Effect of parameters $\phi$ and Re on FoM.

So, although the heat transfer coefficient increases, but overall heat transfer performance decreases as volume fraction increases. As Figure 14 indicates, the FoM remarkably decreases as Reynolds number increases and the best value of 207347 is found at $\operatorname{Re}=50$ and $\phi=1 \%$.

\section{Conclusion}

A numerical analysis of flow and heat transfer characteristics of nanofluid in a parallel plates channel with discrete heat sources has been presented. The heat sources are placed on bottom wall at a constant heat flux and remaining channel surfaces are considered adiabatic. The basefluid is water and three volume fractions of $\mathrm{Al}_{2} \mathrm{O}_{3}$ nanoparticles ( $\phi=0$ (distilled water) 1 and $4 \%$ ) are taken into account with a single-phase model. Furthermore, different Reynolds numbers in the range 50-1000 are considered. The use of nanofluid can cause an asymmetric profile velocity along the height of channel. Results clearly show that the use of nanofluid can remarkably increase heat transfer rate and decrease the wall temperature. Furthermore, for increasing volume fraction, nanofluid can produce lower wall temperature and higher heat transfer rate. The average heat transfer coefficient and pressure profiles present that heat 
transfer rate increases as applied heat flux of heat sources is increased while the pressure drop decreases.

\section{Nomenclature}

\section{Symbols}

$\nabla: \quad$ nabla operatoe $(1 / \mathrm{m})$

$C_{p}: \quad$ specific heat of the fluid $(\mathrm{J} / \mathrm{kg} \mathrm{K})$

FoM: figure of merit

$H$ : channel height $(\mathrm{m})$

$h_{\text {ave }}$ : average heat transfer coefficient along heat sources $\left(\mathrm{W} / \mathrm{m}^{2} \mathrm{~K}\right)$

$k$ : $\quad$ thermal conductivity $(\mathrm{W} / \mathrm{m} \mathrm{K})$

$\dot{m}$ : mass flow rate $(\mathrm{Kg} / \mathrm{s})$

$\mathrm{Nu}: \quad$ local Nusselt number $\left(\mathrm{Nu}=q H /\left(k\left(T_{w}-T_{m}\right)\right)\right)$

$P$ : $\quad$ pressure $(\mathrm{Pa})$

$q$ : $\quad$ heat flux of heat sources $\left(\mathrm{W} / \mathrm{m}^{2}\right)$

Re: reynolds number $\left(\operatorname{Re}=\left(\rho_{\mathrm{nf}} H U_{\mathrm{in}}\right) / \mu_{\mathrm{nf}}\right)$

$s: \quad$ coordinate along heat sources $(\mathrm{m})$

$T: \quad$ temperature $(\mathrm{K})$

$V: \quad$ velocity vector $(\mathrm{m} / \mathrm{s})$

$W: \quad$ total heat transfer rate $(\mathrm{J} / \mathrm{s})$

$U_{\text {in }}$ : inlet velocity $(\mathrm{m} / \mathrm{s})$.

\section{Greeks}

$\eta: \quad$ thermal hydraulic performance factor

$\eta_{\text {pump }}:$ pump efficiency

$\mu$ : dynamic viscosity (Pa.s)

$\rho: \quad$ density $\left(\mathrm{kg} / \mathrm{m}^{3}\right)$

$\phi$ : particle volume fraction (\%).

\section{Subscripts}

$w$ : refers to the wall conditions

bf: refers to the base fluid

nf: refers to the nanofluid

$p$ : refers to particles

$r$ : refers to a ratio

0 : refers to the inlet conditions.

\section{Acknowledgments}

First, the authors would like to thank Editor Dr. M. F. El-Amin and two anonymous referees for their useful suggestions, which greatly improve the paper. We also would like to express 
our appreciation to the Iran nanotechnology initiative council for their financial support for this project.

\section{References}

[1] A.P. Saamito, J.C. Kurnia, and A. S. Mujumdar, "Numerical evaluation of laminar heat transfer enhancement in nanofluid flow in coiled square tube," Nanoscale Research Letter, vol. 6, p. 376, 2011.

[2] G. Roy, S. J. Palm, and C. T. Nguyen, "Heat transfer and fluid flow of nanofluids in laminar radial flow cooling systems," Journal of Thermal Science, vol. 14, no. 4, pp. 362-367, 2005.

[3] S. Lee, S. U. S. Choi, S. Li, and J. A. Eastman, "Measuring thermal conductivity of fluids containing oxide nanoparticles," Journal of Heat Transfer, vol. 121, no. 2, pp. 280-288, 1999.

[4] I. Chopkar, S. Sudarshan, P. K. Das, and I. Manna, "Effect of particle size on thermal conductivity of nanofluid," Metallurgical and Materials Transactions A, vol. 39, no. 7, pp. 1535-1542, 2008.

[5] C. H. Li and G. P. Peterson, "Experimental investigation of temperature and volume fraction variations on the effective thermal conductivity of nanoparticle suspensions (nanofluids)," Journal of Applied Physics, vol. 99, no. 8, Article ID 084314, 2006.

[6] S. K. Das, N. Putra, P. Thiesen, and W. Roetzel, "Temperature dependence of thermal conductivity enhancement for nanofluids," Journal of Heat Transfer, vol. 125, no. 4, pp. 567-574, 2003.

[7] T. P. Teng, Y. H. Hung, T. C. Teng, and J. H. Chen, "Performance evaluation on an air-cooled heat exchanger for alumina nanofluid under laminar flow," Nanoscale Research Letter, vol. 6, p. 488, 2011.

[8] X. Q. Wang and A. S. Mujumdar, "Heat transfer characteristics of nanofluids: a review," International Journal of Thermal Sciences, vol. 46, no. 1, pp. 1-19, 2007.

[9] R. K. Shah and A. L. London, Laminar Flow Forced Convection in Ducts, Academic Press, New York, NY, USA, 1978.

[10] K. B. Anoop, T. Sundararajan, and S. K. Das, "Effect of particle size on the convective heat transfer in nanofluid in the developing region," International Journal of Heat and Mass Transfer, vol. 52, no. 9-10, pp. 2189-2195, 2009.

[11] A. K. Santra, S. Sen, and N. Chakraborty, "Study of heat transfer due to laminar flow of copper-water nanofluid through two isothermally heated parallel plates," International Journal of Thermal Sciences, vol. 48, no. 2, pp. 391-400, 2009.

[12] S. E. B. Maiga, S. J. Palm, C. T. Nguyen, G. Roy, and N. Galanis, "Heat transfer enhancement by using nanofluids in forced convection flows," International Journal of Heat and Fluid Flow, vol. 26, no. 4, pp. 530-546, 2005.

[13] Y. Feng and C. Kleinstreuer, "Nanofluid convective heat transfer in a parallel-disk system," International Journal of Heat and Mass Transfer, vol. 53, no. 21-22, pp. 4619-4628, 2010.

[14] H. Bhowmik, C. P. Tso, K. W. Tou, and F. L. Tan, “Convection heat transfer from discrete heat sources in a liquid cooled rectangular channel," Applied Thermal Engineering, vol. 25, no. 16, pp. 2532-2542, 2005.

[15] A. K. da Silva, S. Lorente, and A. Bejan, "Optimal distribution of discrete heat sources on a plate with laminar forced convection," International Journal of Heat and Mass Transfer, vol. 47, no. 10-11, pp. 2139-2148, 2004.

[16] E. Arquis, M. A. Rady, and S. A. Nada, "A numerical investigation and parametric study of cooling an array of multiple protruding heat sources by a laminar slot air jet," International Journal of Heat and Fluid Flow, vol. 28, no. 4, pp. 787-805, 2007.

[17] E. Jassim and Y. S. Muzychka, "Optimal distribution of heat sources in convergent channels cooled by laminar forced convection," Journal of Heat Transfer, vol. 132, no. 1, pp. 1-8, 2010.

[18] G. Roy, S. J. Palm, and C. T. Nguyen, "Heat transfer and fluid flow of nanofluids in laminar radial flow cooling systems," Journal of Thermal Science, vol. 14, no. 4, pp. 362-367, 2005.

[19] N. Putra, W. Roetzel, and S. K. Das, "Natural convection of nano-fluids," Heat and Mass Transfe, vol. 39, no. 8-9, pp. 775-784, 2003. 


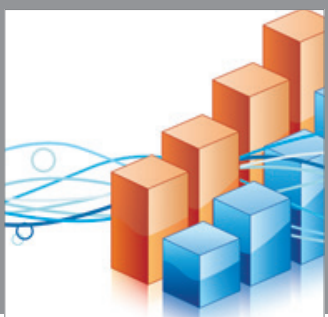

Advances in

Operations Research





\section{The Scientific} World Journal
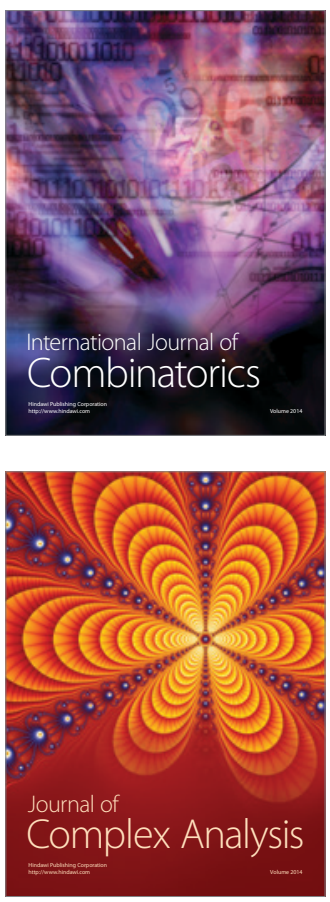

International Journal of

Mathematics and

Mathematical

Sciences


Journal of

Applied Mathematics
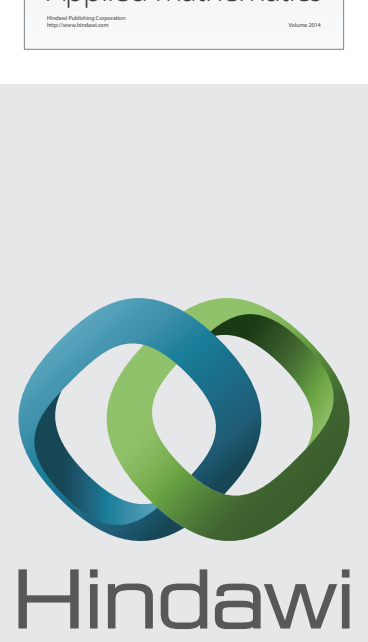

Submit your manuscripts at http://www.hindawi.com
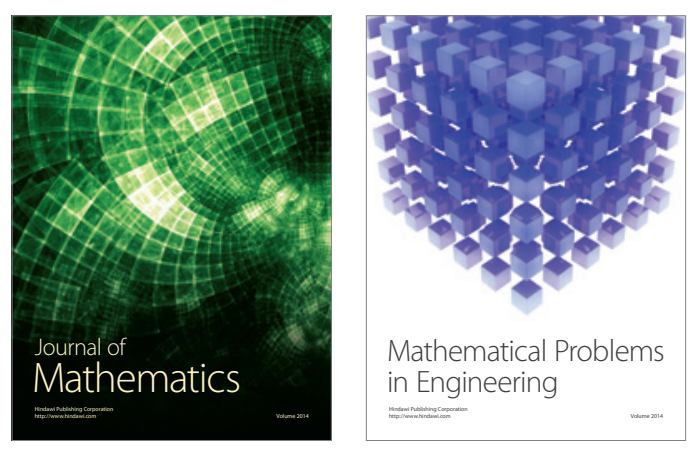

Mathematical Problems in Engineering
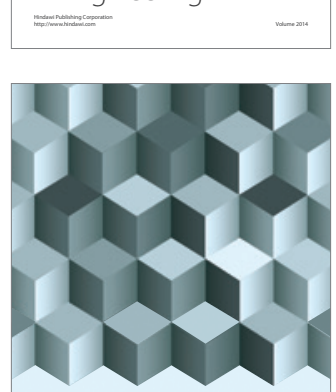

Journal of

Function Spaces
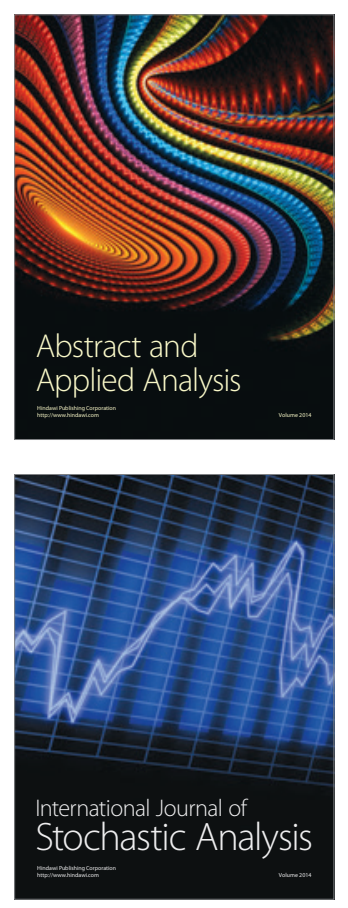

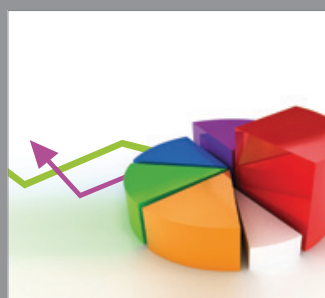

ournal of

Probability and Statistics

Promensencen
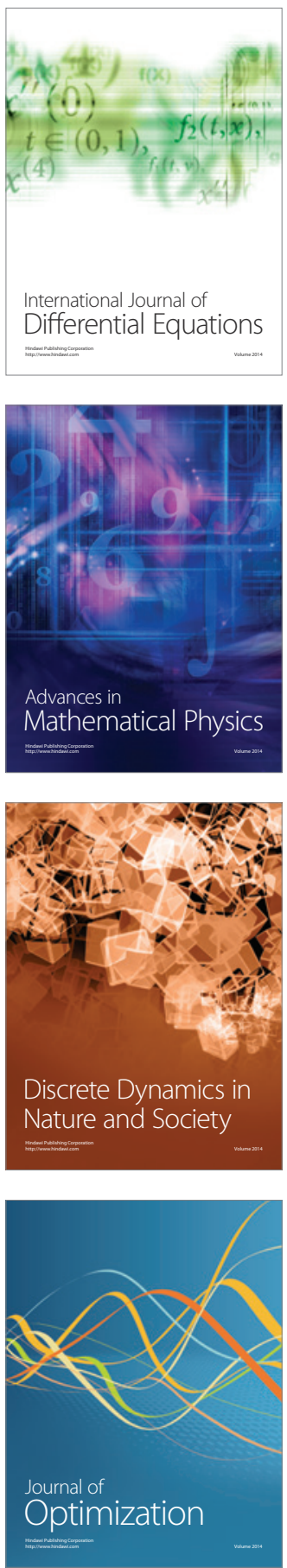